\title{
NILAI EKONOMI KOMODITI HUTAN MANGROVE DI DESA MERAK BELANTUNG KECAMATAN KALIANDA KABUPATEN LAMPUNG SELATAN
}

\section{(THE ECONOMIC VALUE OF MANGROVE FOREST COMMODITY IN MERAK BELANTUNG VILLAGE KALIANDA DISTRICT SOUTH LAMPUNG REGENCY)}

\author{
Dewi Masithah, Asihing Kustanti, dan Rudi Hilmanto \\ Jurusan Kehutanan Fakultas Pertanian Universitas Lampung \\ Jl. Soemantri Brojonegoro no. 1 Bandar Lampung \\ E-mail: dewimasithah10@yahoo.com No. Hp: 082186166209
}

\begin{abstract}
ABSTRAK
Hutan mangrove merupakan formasi vegetasi hutan tropis dan sub tropis yang didominasi oleh beberapa pohon mangrove yang mampu tumbuh dan berkembang di daerah pasang surut pantai berlumpur. Hutan mangrove di Desa Merak Belantung Kecamatan Kalianda Kabupaten Lampung Selatan memiliki komoditi- komoditi yang bernilai ekonomi dan dapat bermanfaat bagi masyarakat sekitarnya. Nilai ekonomi tersebut diketahui dengan melalukan wawancara kepada responden penelitian. Komoditi hutan mangrove yang bernilai ekonomi yaitu ikan kakap (Lutjanus sp.), ikan belana (Valamugil seheli), ikan gelodok (Valamugil seheli), kerang tiram (Crassostrea gigas), kerang lukan (Geloina erosa), kepiting (Brachyura), udang windu (Penaeusmonodon), dan buah pidada (Sonneratia caseolaris). Nilai ekonomi dari komoditi hutan mangrove dapat diketahui dan dihitung menggunakan metode penilaian berdasarkan harga pasar dan metode kesediaan menerima pembayaran (WTA). Nilai ekonomi seluruh komoditi hutan mangrove Desa Merak Belantung Kecamatan Kalianda Kabupaten Lampung Selatan adalah sebesar Rp 754.090.000 per tahun untuk 8 jenis komoditi yang dihasilkan.
\end{abstract}

Kata kunci : komoditi hutan mangrove, penilaian berdasarkan harga pasar, kesediaan untuk menerima (WTA)

\section{ABSTRACT}

Mangrove forest was a tropical and sub tropical forests vegetation. It dominated by some of mangrove trees which it growed and developed in the tidal muddy along the coastal area. The mangrove forest of Merak Belantung of South Lampung had some commodities which it had a economic value and could benefits for the community. The economic value information aimed by interview the respondents. The economic comodities of mangrove were fishes namely: kakap (Lutjanus sp.), belanak (Valamugil seheli), gelodok (Periophthalus modestus), and varieties of seashells (tiram (Crassostrea gigas) and lukan (Geloina erosa)), crabs (Brachyura), shrimp (Penaeusmonodon), and sonneratia fruit (Sonneratia caseolaris). The economic value of commodities could discovered and calculated with assessment based on market valuation and willingness to accept payment (WTA) methods. Total economic value from mangrove forest commodities was IDR 754.090.000/year from 8 types commodity.

Key word : mangrove forest commodity, assessment based on market value, willingness to accept (WTA) 


\section{PENDAHULUAN}

Hutan mangrove adalah salah satu ekosistem hutan yang terletak diantara daratan dan lautan. Hutan tersebut mempunyai karakteristik unik dibandingkan dengan formasi hutan lainnya. Keunikan tersebut terletak pada keanekaragaman flora, fauna, dan habitat tempat hidupnya (Kustanti, 2011). Secara garis besar fungsi ekonomis mangrove merupakan sumber pendapatan bagi masyarakat, industri maupun bagi negara. Perhitungan nilai ekonomi sumberdaya mangrove adalah suatu upaya melihat manfaat dan biaya dari sumberdaya dalam bentuk moneter yang mempertimbangkan lingkungan (Arief, 2003).

Perhitungan nilai ekonomi terhadap komoditi hutan mangrove bertujuan untuk memberikan gambaran potensi ekonomi hutan mangrove yang dapat dimanfaatkan secara langsung bagi kehidupan dan dapat digunakan sebagai acuan dalam aktivitas pemanfaatan serta memberikan gambaran pola pengelolaan yang akan dilakukan. Nilai ekonomi nilai guna langsung juga menunjukkan tingkat optimalisasi pemanfaatan yang telah dilakukan di kawasan hutan mangrove tersebut, sehingga terjadinya pemanfaatan mangrove tidak memberikan dampak buruk dan degradasi mangrove di masa mendatang (Qodrina dkk., 2012).

Desa Merak Belantung terletak di wilayah pesisir dan memiliki sumberdaya alam hutan mangrove yang melimpah. Hutan mangrove Desa Merak Belantung memiliki manfaat yang besar dari segi ekonomi, ekologi, dan sosial bagi masyarakat sekitarnya, namun hanya sedikit masyarakat Desa Merak Belantung yang mengetahui manfaat langsung dan tidak langsung dari keberadaan hutan mangrove dan terlebih terhadap nilai guna langsung yang memiliki potensi ekonomi yang secara tidak sadar telah mereka dapatkan. Potensi ekonomi dari komoditi hutan mangrove Desa Merak Belantung dapat diketahui dengan melakukan kajian mendalam dari berbagai aspek, sehingga diperlukan penelitian guna mengetahui berbagai komoditi hutan mangrove yang memiliki nilai ekonomi dan nilai ekonomi dari masingmasing komoditi tersebut, menghitung total nilai ekonomi komoditi yang dihasilkan hutan mangrove, serta mengetahui jenis dan dominasi mangrove penyusun hutan mangrove Desa Merak Belantung Kecamatan Kalianda Kabupaten Lampung Selatan yang diharapkan dapat meningkatkan kesejahteraan masyarakat dan menjaga kelestarian alam.

\section{METODE PENELITIAN}

\section{A. Tempat dan Waktu Penelitian}

Penelitian dilaksanakan pada bulan Desember-Februari 2015, di hutan mangrove Desa Merak Belantung Kecamatan Kalianda Kabupaten Lampung Selatan.

\section{B. Objek dan alat penelitian}

Objek dalam penelitian ini yaitu hutan mangrove Desa Merak Belantung yang dimanfaatkan oleh masyarakat dan dikelola oleh masyarakat dan Dinas Kehutanan. Alat bantu dalam penelitian yaitu daftar kuesioner, seperangkat alat komputer, kamera dan alatalat tulis.

\section{Metode Pengumpulan Data}

Jenis data yang dikumpulkan dalam penelitian ini adalah data primer dan data skunder. Data primer didapatka dari hasil wawancara menggunakan kuesioner dan pengamatan analisis vegetasi. Data primer yang dibutuhkan menggunakan wawancara/kuesioner tentang nilai ekonomi komoditi hutan mangrove yang memiliki pasar dan nilai ekonomi komoditi hutan mangrove yang tidak memiliki pasar dengan mengestimasi kesediian untuk menerima (WTA) dari komoditi tersebut, serta data analisis vegetasi hutan mangrove. Data Sekunder 
yang digunakan dalam penelitian ini didapatkan dari instansi yang terkait yaitu kantor Kepala Desa, Kelurahan, dan Dinas Kehutanan. Data sekunder ini berupa data gambaran umum lokasi penelitian dan luasan hutan mangrove.

\section{Metode Pengambilan Sampel}

Pengambilan sampel dalam penelitian menggunakan Snowball sampling sehingga didapatkan 8 komoditi hutan mangrove Desa Merak Belantung yang memiliki potensi ekonomi. Kemudian untuk mengetahui nilai ekonomi dari masing-masing komoditi hutan tersebut dilakukan pengambilan sampel menggunakan metode simple random sampling.

Jumlah nelayan di Desa Merak Belantung yaitu 116 orang (Profil Desa Merak Belantung, 2014). Banyaknya responden ditentukan dengan menggunakan presisi $15 \%$, karena dilihat dari segi keterbatasan waktu, biaya, dan tenaga. Menurut Arikunto (2013), maka didapatkan responden:

$$
\begin{aligned}
& \mathrm{n}=\frac{\mathrm{N}}{\mathrm{N} \mathrm{e}^{2}+1} \\
& \mathrm{n}=\frac{116}{1160,15^{2}+1}=\frac{116}{3,61}=32 \text { responden }
\end{aligned}
$$

Keterangan:

$\mathrm{n}$ : jumlah responden

$\mathrm{N}$ : jumlah seluruh nelayan

e : presisi $15 \%$

1 : bilangan konstan

\section{E. Analisis Data}

a. Analisis Vegetasi

Analisis vegetasi hutan mangrove Desa Merak Belantung dilakukan dengan menggunakan metode garis berpetak dengan plot berukuran $(10 \mathrm{~m} \times 10 \mathrm{~m})$. Intensitas sampling yang digunakan yaitu $1 \%$ untuk luas kawasan hutan mangrove tempat penelitian sebesar $10 \mathrm{Ha}$ (Dinas Kehutanan Lampung Selatan, 2014). Rumus penentuan banyaknya jumlah plot dalam penelitian ini adalah (Indriyanto, 2010):

$$
\begin{aligned}
\ell & =\mathrm{L} \times \mathrm{Is} \\
& =10 \mathrm{Ha} \times 1 \% \\
& =100000 \mathrm{~m} \times 0,01=1000 \mathrm{~m}
\end{aligned}
$$

Banyaknya plot penelitian : $\frac{\ell}{\text { Luas plot contoh }}=\frac{1000}{100}=10$ plot

Keterangan:

$\ell \quad:$ luas seluruh plot penelitian

L : Luas kawasan penelitian

Is : Intensitas sampling

Variabel yang dihitung dalam analisis vegetasi (Indriyanto, 2010) :

1. Kerapatan $(\mathrm{K})$

$$
\mathrm{K}=\frac{\text { Jumlah individu }}{\text { Luas seluruh petak contoh }}
$$


2. Kerapatan Relatif (KR)

$$
\mathrm{KR}=\frac{\text { jumlah individu suatu spesies }}{\text { jumlah individu semua spesies pohon }} \times 100 \%
$$

3. Frekuensi (F)
$\mathrm{F}=$
Jumlah petak contoh ditemukannya suatu spesies

4. Frekuensi Relatif (FR)

$$
\mathrm{FR}=\quad \frac{\text { Frekuensi suatu spesie }}{\text { Frekuensiseluruh spesies }} \times 100 \%
$$

5. Dominasi (D)

6. Dominasi Relatif (DR)

$$
\mathrm{D}=\frac{\text { Luas bidang dasar suatu petak contoh }}{\text { Luas seluruh petak contoh }}
$$

$\mathrm{DR}=\frac{\text { Dominasi suatu spesies }}{\text { Dominasi seluruh spesies }} \times 100 \%$

7. Indeks Nilai Penting (INP) menurut Curtis dan Mc. Intosh (dikutip oleh Indriyanto, 2010:

$\mathrm{INP}=K R+F R+D R$

b. Data komoditi hutan mangrove yang memiliki potensi ekonomi dari hasil observasi di lapangan serta pendapat para pihak secara snowball dianalisis secara deskriptif.

c. Pendugaan Nilai Ekonomi Komoditi Langsung Hutan Mangrove

1. Penilaian berdasarkan harga pasar, untuk komoditi hutan mangrove yang telah memiliki pasar.

2. Kesediaan menerima pembayaran (Willingness to accept/WTA), untuk komoditi hutan mangrove yang tidak memiliki pasar.

Analisis kesediaan menerima (WTA) masyarakat

Cara untuk mengetahui nilai WTA masyarakat dalam penelitian ini adalah dengan menghitung nilai rataan WTA dan menghitung total WTA Hanley and Spash, 1993 dalam Arafat dkk., 2015.

a. Memperkirakan Nilai Rataan WTA

Dugaan nilai rataan WTA dihitung dengan rumus:

$$
\mathrm{EWTA}=\frac{\sum_{t=0}^{n} \mathrm{WTA} \mathrm{x}_{\mathrm{i}}}{}
$$

$$
\text { n }
$$

dimana:

EWTA : Dugaan nilai rataan WTA

WTA : nilai WTA komoditi

$\mathrm{Xi} \quad$ : Jumlah tiap data

n : Jumlah responden

i $\quad$ : Responden ke-I yang bersedia menerima kompensasi $(i=1,2, \ldots, k)$

b. Menghitung Total WTA

Penjumlahan data merupakan proses dimana nilai tengah penawaran dikonversikan terhadap populasi yang dimaksud. Setelah menduga nilai tengah WTA maka dapat diduga nilai WTA dari masyarakat dengan rumus: 
n

TWTA $=\underset{t=0}{\sum}$ WTAi ni

dimana:

TWTA : Total WTA

EWTAi : Nilai rata-rata WTA

ni : Jumlah komoditi

i : Responden ke-I yang bersedia menerima kompensasi $(i=1,2, \ldots, \ldots \mathrm{k})$

\section{HASIL DAN PEMBAHASAN}

\section{A. Analisis vegetasi}

Berdasarkan penelitian Saputra (2013) ditemukan 15 spesies pohon mangrove di hutan mangrove Desa Merak Belantung yang terdiri dari 9 famili dan tergolong kedalam 3 kelompok mangrove yaitu kelompok mangrove mayor, minor dan asosiasi. Kelompok mayor merupakan komponen yang memperlihatkan karakter morfologi, seperti mangrove yang memiliki sistem perakaran udara dan mekanisme fisiologi khusus untuk mengeluarkan garam agar dapat menyesuaikan diri dengan lingkungannya. Kelompok minor adalah komponen yang tidak termasuk elemen yang menyolok dari tumbuhan-tumbuhan yang mungkin terdapat di sekeliling habitatnya dan yang jarang berbentuk tegakan murni, sedangkan kelompok asosiasi merupakan komponen yang jarang ditemukan spesies yang tumbuh di dalam komunitas mangrove yang sebenarnya dan kebanykan sering ditemukan dalam tumbuhtumbuhan darat (Kustanti, 2011). Data jenis-jenis pohon mangrove yang ada di Desa Merak Belantung dapat dilihat pada Tabel 1.

Tabel 1. Jenis mangrove yang terdapat di hutan mangrove desa Merak Belantung Kecamatan Kalianda Kabupaten Lampung Selatan.

\begin{tabular}{lllll}
\hline No. & Nama lokal & Nama Ilmiah & Famili & $\begin{array}{l}\text { Kelompok } \\
\text { Mangrove }\end{array}$ \\
\hline 1. & Api-api & Avivennia alba & Avicenniaceae & Mayor \\
2. & Api-api & Avicennia marina & Avicenniaceae & Mayor \\
3. & Mengadai & Lumnitzera racemosa & Combretaceae & Minor \\
4. & Buta-buta & Excoecaria agallocha & Euphorbiaceae & Asosiasi \\
5. & Teruntum & Aegiceras corniculatum & Myrsinaceae & Asosiasi \\
6. & Nipah & Nyapa fruticans & Palmae & Minor \\
7. & Tanjang putih & Bruguiera cylindrica & Rhiziphoraceae & Mayor \\
8. & Tanjang merah & Bruguiera gymnorrizha & Rhiziphoraceae & Mayor \\
9. & Mentigi & Ceriops tagal & Rhiziphoraceae & Mayor \\
10. & Bakau kecil & Rhizophora apiculata & Rhiziphoraceae & Mayor \\
11. & Bakau besar & Rhizophora mucronata & Rhiziphoraceae & Mayor \\
12. & Duduk rambat & Scyphipora hydruphyllacea & Rubiaceae & Asosiasi \\
13. & Pidada, bogem & Sonneratia alba & Sonneratiaceae & Mayor \\
14. & Pidada, bogem & Sonneratia caseolaris & Sonneratiaceae & Mayor \\
15. & Bayur Laut & Heritiera littoralis & Sterculiaceae & Asosiasi \\
\hline (Sum & ber: Data skunder & 2013) & &
\end{tabular}

(Sumber: Data skunder, 2013).

Berdasarkan Tabel 1 diketahui bahwa sebagian besar jenis pohon mangrove yang terdapat pada hutan mangrove desa Merak Belantung adalah dari famili Rhizophoraceae sebanyak 5 pohon mangrove yaitu bakau besar (Rhizophora mucronata), bakau kecil ( $R$. 
apiculata), mentigi (Ceriops tagal), tanjung putih (Bruguiera cylindrica), dan tanjung merah (Bruguiera gymnorrizha). Jenis pohon mangrove desa Merak Belantung juga didominasi oleh kelompok mangrove mayor yang terbagi menjadi 4 famili mangrove, yaitu Avicenniaceae, Rhizophoraceae, Palmae, dan Sonneratiaceae (Saputra, 2013).

Berdasarkan analisis vegetasi hutan mangrove diketahui Indeks Nilai Penting didapatkan dari penjumlahan Kerapatan Relatif (KR), Frekuensi Relatif (FR), dan Dominansi Relatif (DR) dari masing-masing spesies pohon mangrove. Hasil analisis vegetasi dari masing-masing jenis pohon mangrove yang ada di Desa Merak Belantung dapat dilihat pada Tabel 2.

Tabel 2. Hasil analisis vegetasi pohon mangrove di Desa Merak Belantung Kecamatan Kalianda Kabupaten Lampung Selatan.

\begin{tabular}{|c|c|c|c|c|c|c|}
\hline No. & Nama Lokal & Nama Ilmiah & $\begin{array}{l}\mathrm{KR} \\
(\%)\end{array}$ & $\begin{array}{l}\text { FR } \\
(\%)\end{array}$ & $\begin{array}{l}\mathrm{DR} \\
(\%)\end{array}$ & $\begin{array}{l}\text { INP } \\
(\%)\end{array}$ \\
\hline 1. & $\overline{\text { Baka }}$ & Rhizophora mисronata & 30,51 & 33,33 & 69,76 & 133,60 \\
\hline 2. & Bakau kecil & Rhizophora apiculata & 55,10 & 22,22 & 17,13 & 94,45 \\
\hline 3. & Mengadai & Lumnitzera racemosa & 11,86 & 33,33 & 7,71 & 52,90 \\
\hline \multirow[t]{2}{*}{4.} & Api-api & Avicennia alba & 2,54 & 11,11 & 5,40 & 19,05 \\
\hline & & Total & 100,00 & 100,00 & 100,00 & 300,00 \\
\hline
\end{tabular}

Sumber: Data primer, 2015.

Berdasarkan analisis vegetasi di hutan mangrove Desa Merak Belantung menggunakan metode garis berpetak dengan jumlah 10 plot ditemukan 4 spesies pohon mangrove di dalam plot tersebut dan dapat dilihat pada tabel 2. Berdasarkan hasil analisis pada tabel 2 dapat diketahui bahwa kerapatan relatif pada hutan mangrove Desa Merak Belantung yang tertinggi adalah pada pohon bakau kecil (Rhizophora apiculata) sebesar 55,1\%, sedangkan pohon yang memiliki kerapatan relatif terendah adalah pohon api-api (Avicennia alba) sebesar $2,54 \%$. Frekuensi relatif tertinggi terdapat pada 2 jenis pohon mangrove, yaitu pohon bakau besar (Rhizophora mucronata) dan mengadai (Lumnitzera racemosa) karena kedua pohon tersebut memiliki frekuensi relatif $33,33 \%$, sedangkan pohon mangrove yang memiliki frekuensi relatif terendah adalah pohon api-api (Avicennia alba) sebesar 11,11\%. Pohon mangrove yang memiliki dominansi relatif tertinggi adalah pohon bakau besar (Rhizophora mucronata) sebesar $69,76 \%$, sedangkan pohon mangrove yang memiliki dominansi relatif terendah adalah pohon api-api (Avicennia alba) sebesar 5,4\%.

Jenis pohon mangrove di Desa merak Belantung Kecamatan Kalianda Kabupaten Lampung selatan yang memiliki indeks nilai penting terbesar adalah pohon bakau besar (Rhizophora mucronata) sebesar $133,6 \%$, sedangkan pohon mangrove yang memiliki indeks nilai penting terendah adalah pohon api-api (Avicennia alba) sebesar 19,05\%. Indeks nilai penting merupakan parameter suatu janis pohon dapat dikatakan sebagai penguasa dalam suatu komunitas karena jika dalam suatu komunitas terdapat pohon yang memiliki indeks nilai penting tertinggi makan pohon tersebut dikatakan lebih dominan dan menguasai suatu komunitas tersebut (Indriyanto, 2010).

Jenis Rhizopora spp. umumnya mampu hidup pada substrat berlumpur dan berpasir. Bengen (1999) dan Arief (2003) menyatakan bahwa jenis Rhizophora sp. umumnya tumbuh di daerah yang bersubstrat lunak, dan memiliki penyebaran yang luas. Menurut Abdulhaji (2011) bahwa sebagian besar hutan mangrove yang ada di Indonesia didominasi oleh famili Rhizophoracaceae. 
Steenis dalam Aksornkoae (1993) menyatakan bahwa Rhizophora mucronata akan tumbuh dengan baik pada tipe substrat lumpur yang relatif tebal, $\mathrm{pH}$ tanah berkisar 6,2 - 6,6, serta berkembang dengan baik pada kisaran salinitas 10 - 30\%o (Bengen dan Dutton, 2004).

Berdasarkan pada hasil penelitian yang dilaporkan oleh Barkey dalam Erwin (2005) bahwa jenis Rhizophora spp. berkembang pada tanah-tanah yang relatif lebih kasar dibandingkan dengan Avicennia spp., tetapi secara umum masih dapat digolongkan pada tanah bertekstur halus. Kadar bahan organik pada tanah dibawah tegakan Rhizophora apiculata pada umumnya relatif tinggi dan salinitas tanah yang sedang. Avicennia alba mampu beradaptasi pada keadaan salinitasnya yang cukup tinggi. Menurut Syahril (1995) pada umumnya Bruguiera gymnorrhiza tumbuh baik pada substrat berupa tanah kering dengan genangan pasang tidak menentu dan salinitas berada di bawah 25\%o. Menurut Barkey dalam Alik, dkk.,(2013), bahwa jenis Avicennia spp. dan Sonneratia spp. umumnya berkembang pada tanah bertekstur halus, kaya akan bahan organik, dan salinitas tinggi.

Menurut Setyawan, dkk. (2005) sedikitnya jumlah spesies mangrove disebabkan oleh besarnya pengaruh antropogenik yang mengubah habitat mangrove untuk kepentingan lain seperti pembukaan lahan untuk pertambakan dan pemukiman. Lebih lanjut menurut Heddy dan Kurniaty dalam Suwondo (2006) bahwa rendahnya keaneka-ragaman menandakan ekosistem mengalami tekanan atau kondisi lingkungan telah mengalami penurunan, hal ini bisa terjadi karena mangrove hidup pada lingkungan ekstrim seperti kadar garam yang tinggi serta substrat yang berlumpur, sehingga untuk dapat hidup harus melalui seleksi yang sangat ketat dan daya adaptasi yang tinggi, juga dapat di sebabkan karena aktivitas manusia. Tingginya tingkat eksploitasi, habitat yang tidak cocok, dan adanya interaksi antar spesies dapat menyebabkan rendahnya frekuensi kehadiran jenis mangrove di suatu lokasi (Kepel, dkk., 2012).

Spesies Sonneratia alba tumbuh pada substrat lumpur berpasir dan banyak ditemukan pada daerah tepian yang menjorok ke laut dengan salinitas yang relatif tinggi yang berkisar 24,3\%o. Noor, dkk. (1999) menyatakan bahwa Sonneratia alba adalah jenis tumbuhan pionir yang tidak toleran terhadap air tawar dalam periode lama, menyukai tanah yang bercampur lumpur dan pasir, kadang-kadang pada batuan dan karang. Areal hutan mangrove di Pesisir Mara'bombang pada umumnya telah dikonversi menjadi tambak dan permukiman penduduk. Kondisi ini menyebabkan kelestarian mangrove di daerah ini terancam rusak, akibat aktivitas penebangan yang tidak diikuti dengan penanaman. Aktivitas penduduk yang bermukim di sekitar pantai menghasilkan banyak limbah rumah tangga dan sampah-sampah anorganik yang dibuang ke laut, sehingga terperangkap oleh akar dan menutupi lentisel akar mangrove, dan mengurangi suplai oksigen untuk proses transpor aktif di akar (Alik, dkk., 2013).

Sifat fisik tanaman pada hutan mangrove dapat membantu pengendapan lumpur. Pengendapan lumpur berhubungan erat dengan penghilangan racun dan unsur hara air karena banyak racun yang memasuki ekosistem perairan dalam keadaan terikat pada permukaan lumpur atau terdapat di antara kisi-kisi molekul partikel air tanah. Beberapa spesies tertentu dalam hutan mangrove bahkan membantu proses penambatan racun secara aktif (Arief, 2003), sehingga dengan adanya hutan mangrove kualitas air laut terjaga dari endapan lumpur erosi dan racun-racun. Hutan mangrove juga memiliki hasil alam in-situ yaitu mencakup semua fauna yang dapat dimanfaatkan secara langsung di dalam kawasan hutan mangrove seperti ikan, udang, kepiting, kerang, dan buah mangrove yang dapat dimanfaatkan sebagai makana atau diolah sebagai minuman yang bisa dikonsumsi dan menghasilkan nilai ekonomi yang dapat menambah pendapatan masyarakat. Sedangkan sumber alam ex-situ meliputi produk-produk alamiah di hutan mangrove dan terangkut/ berpindah ke tempat lain yang kemudian digunakan oleh masyarakat di daerah tersebut, menjadi sumber makanan bagi organisme lain atau menyediakan fungsi lain seperti menambah luas pantai karena pemindahan pasir dan lumpur. 


\section{B. Potensi Ekonomi Komoditi Langsung Hutan Mangrove}

Berdasarkan hasil observasi di lapangan dan pendapat responden penelitian secara snowball didapatkan informasi mengenai komoditi hutan mangrove di Desa Merak Belantung yang memiliki nilai ekonomi adalah ikan kakap, ikan belana, ikan belodok, udang windu, kerang tiram, kerang lokan, kepiting, dan buah pidada. Tidak semua masyarakat Desa Merak Belantung mencari dan memanfaatkan komoditi langsung hutan mangrove untuk mereka jual, tetapi ada juga beberapa masyarakat yang mencari komoditi langsung hutan mangrove hanya untuk mengisi waktu senggang mereka dengan mencari komoditi langsung hutan mangrove tersebut untuk dikonsumsi pribadi, dan tidak sedikit pula masyarakat yang menjaring udang sebagai umpan memancing ikan untuk menyalurkan hobinya.

Ekosistem mangrove merupakan penghasil detritus, sumber nutrient dan bahan organik yang dibawa ke ekosistem padang lamun oleh arus laut. Secara ekologis hutan mangrove merupakan daerah asuhan (nursery ground), daerah pencari makan (feeding ground) dan daerah pemijahan (spawning ground) bermacam biota perairan, baik yang hidup di perairan pantai maupun lepas pantai. Hal ini yang menyebabkan terjadinya interaksi atau asosiasi antara fauna dengan mangrove (Mustari, 2005).

Hutan mangrove berfungsi sebagai tempat mencari makan, berlindung, memijah dan pembesaran bagi berbagai jenis binatang air seperti ikan, udang, dan kepiting. Kondisi perairan yang tenang serta terlindung dengan berbagai macam tumbuhan dan bahan makanan menyebabkan perairan hutan mangrove menjadi tempat yang sangat baik untuk berkembang biak bagi berbagai satwa. Terkait dengan sifat fauna yang pada umumnya sangat dinamis, maka batasan zonasi yang terjadi pada fauna penghuni mangrove kurang begitu jelas (Kartawinata, dkk., 1979).

Tabel 3. Nilai ekonomi komoditi hutan mangrove Desa Merak Belantung.

\begin{tabular}{|c|c|c|c|c|c|}
\hline No. & $\begin{array}{l}\text { Komiditi } \\
\text { Langsung }\end{array}$ & $\begin{array}{l}\text { Komoditi } \\
\text { Tidak } \\
\text { Langsung }\end{array}$ & $\begin{array}{l}\text { Nama } \\
\text { Ilmiah }\end{array}$ & $\begin{array}{c}\text { Frekuensi } \\
\text { (Responden) }\end{array}$ & $\begin{array}{c}\text { Nilai Ekonomi } \\
\text { (Rp/Komoditi/T } \\
\text { ahun) }\end{array}$ \\
\hline 1. & $\begin{array}{l}\text { Buah } \\
\text { pidada }\end{array}$ & - & Sonneratia caseolaris & 1 & 2.190 .000 \\
\hline 2. & - & Ikan kakap & Lutjanus sp. & 5 & 65.700 .000 \\
\hline 3. & - & Ikan belanak & Valamugil seheli & 5 & 65.700 .000 \\
\hline 4. & - & Udang windu & Penaeusmonodon & 4 & 127.750 .000 \\
\hline 5. & - & Kerang lukan & Geloina erosa & 4 & 54.750 .000 \\
\hline 6. & - & Kerang tiram & Crassostrea gigas & 6 & 109.500 .000 \\
\hline 7. & - & Kepiting & Brachyura & 6 & 255.500 .000 \\
\hline 8. & - & Ikan gelodok & Periophthalus modestus & 1 & 73.000 .000 \\
\hline \multicolumn{4}{|c|}{ Total } & 32 & 754.090 .000 \\
\hline
\end{tabular}

(Sumber: Data primer, 2015).

\section{Pendugaan Nilai Ekonomi Komoditi Hutan Mangrove}

1. Penilaian berdasarkan harga pasar

Komoditi hutan mangrove Desa Merak Belantung yang memiliki nilai pasar adalah ikan kakap, ikan belanak, ikan belodok, udang windu, kerang tiram, kerang lokan, dan kepiting. Berdasarkan Tabel 3 diketahui bahwa komoditi hutan mangrove Desa Merak Belantung yang memiliki nilai ekonomi tertinggi adalah kepiting yaitu sebesar Rp 219.000.000/tahun dan komoditi yang memiliki nilai ekonomi terendah adalah ikan belanak dan kerang tiram yaitu sebesar Rp 18.250.000/tahun. 
2. Metode kesediaan menerima (Willingness to accept/WTA)

Komoditi hutan mangrove Desa Merak Belantung yang tidak memiliki nilai pasar adalah buah pidada. Nilai ekonomi dari buah pidada diketahui dengan menggunakan metode kesediaan menerima pembayaran, responden yang bersedia menerima pembayaran untuk komoditi hutan mangrove buah pidada ini adalah 1 orang karena menurut responden komoditi tersebut dapat dikonsumsi sebagai lauk pendamping makan atau dapat diolah menjadi sirup yang bisa diminum.

Tabel 4. Besaran nilai WTA dan nilai rataan WTA responden.

\begin{tabular}{llcccc}
\hline No. & $\begin{array}{c}\text { Nama } \\
\text { Komoditi }\end{array}$ & $\begin{array}{c}\text { Nilai WTA } \\
\text { (Rp/Komoditi/ } \\
\text { Tahun) }\end{array}$ & $\begin{array}{c}\text { Frekuensi } \\
\text { (Responden) }\end{array}$ & $\begin{array}{c}\text { Frekuensi } \\
\text { Relatif }\end{array}$ & $\begin{array}{c}\text { Mean WTA } \\
\text { (RP/Komoditi/ } \\
\text { Tahun) }\end{array}$ \\
\hline 1. & Buah Pidada & 2.190 .000 & 1 & 1 & 2.190 .000 \\
\hline & Total & & 1 & 1 & 2.190 .000 \\
\hline
\end{tabular}

(Sumber: Data primer, 2015).

\section{Dugaan nilai rataan WTA (EWTA)}

Dugaan nilai rataan responden didapatkan dari data distribusi kesediaan menerima pembayaran (WTA) masing-masing responden. Perhitungan nilai rataan WTA dapat dilihat pada tabel 4.

Berdasarkan Tabel 4 diketahui bahwa hanya 1 responden yang mengetahui manfaat dari buah pidada yang memiliki potensi ekonomi. Dugaan nilai rataan WTA dari komoditi hutan mangrove buah pidada ini adalah sebesar Rp 2.190.000/tahun.

\section{Nilai Total WTA}

Total nilai WTA responden terhadap komoditi hutan mangrove Desa Merak Belantung buah pidada diperoleh dari perkalian nilai rataan responden dengan jumlah komoditi hutan mangrove dari Desa Merak Belantung yang tidak memiliki pasar dan harga pasar, berdasarkan perhitungan tersebut didapatkan hasil sebesar $\mathrm{Rp} 2.190 .000$ per tahun. Nilai tersebut merupakan total nilai kesediaan menerima pembayaran atas komoditi hutan mangrove Desa Merak Belantung Kecamatan Kalianda Kabupaten Lampung Selatan yang tidak memiliki harga pasar dan pasar.

Hanya sebagian kecil masyarakat yang mengetahui bahwa buah ini dapat dikonsumsi sebagai lauk pendamping makan (lalapan) atau diolah menjadi minuman, sehingga kesediaan responden menerima pembayaran untuk komoditi ini pun rendah.

Hutan mangrove Desa Merak Belantung kondisinya tidak terlalu terawat karena hanya beberapa masyarakat yang mengetahui fungsi dan manfaat dari keberadaan hutan mangrove bagi daerah pinggir pantai dan pentingnya hutan mangrove bagi kehidupan. Hanya masyarakat yang memanfaatkan hasil hutan mangrove untuk memenuhi kebutuhan hidup atau mendapatkan tambahan biaya kehidupan yang merawat dan menjaga kelestarian hutan mangrove Desa Merak Belangtung.

Hasil penelitian Ariftia, dkk. (2013) diketahui nilai guna langsung hutan mangrove Desa Margasari tentang manfaat yang langsung diambil dari sumberdaya alam hutan mangrove. Berdasarkan hasil penelitian ini, nilai guna langsung hutan mangrove bagi masyarakat yaitu pemanfaatan rajungan, udang, kepiting, daun jeruju, buah pidada, kayu bakar dan ekowisata adalah sebesar Rp 1.877.440.000/tahun.

Pada penelitian yang dilakukan oleh Agustina, dkk. (2014) mengenai kegiatan pengambilan biota di ekosistem padang lamun Desa Berakit yang memberikan nilai manfaat langsung diantaranya pengambilan kepiting (Brachyura), gonggong (Strombus canarium), 
kerang (Anadara granosa), teripang (Holothuria scaba), ikan lebam (Siganus javus), ikan lingkis (Siganus javus) dan sotong (Sephia officinalis). Nelayan yang biasa memanfaatkan atau mengambil biota yang hidup di padang lamun sebanyak 60 orang nelayan. Berdasarkan pengamatan struktur komunitas padang lamun di Desa Berakit, diperoleh jenis lamun yang ditemukan merupakan jenis lamun yang biasanya dijadikan habitat oleh beberapa biota tersebut. Biota yang berhabitat di padang lamun antara lain kerang (Anadara granosa), sotong (Sephia officinalis), dan teripang (Holothuria scaba) (Kordi, 2011). Dari hasil penelitian nilai manfaat langsung ekosistem padang lamun di Desa Berakit yakni Rp 1.107.360.000/tahun.

\section{KESIMPULAN}

\section{A. Kesimpulan}

1. Komoditi hutan mangrove Desa Merak Belantung yang memiliki nilai ekonomi yaitu ikan kakap, ikan belana, ikan belodok kerang tiram, kerang lokan, kepiting, udang windu, dan buah pidada.

2. Nilai ekonomi ikan kakap Rp 65.700.000/tahun, ikan belanak Rp 65.700.000/tahun, udang windu Rp 127.750.000/tahun, kerang tiram Rp 109.500.000/tahun, kerang lokan Rp 54.750.000/tahun, kepiting Rp 255.500.000/tahun, ikan belodok Rp 73.000.000/tahun, dan buah pidada Rp 2.190.000/tahun.

3. Nilai ekonomi seluruh komoditi hutan mangrove Desa Merak Belantung sebesar Rp 754.090.000 per tahun untuk 8 jenis komoditi yang dihasilkan langsung oleh hutan mangrove.

4. Terdapat 15 jenis pohon mangrove pada hutan mangrove Desa Merak Belantung, terdiri dari 9 famili dan tergolong dalam 3 kelompok mangrove yang didominasi (dikuasai) oleh pohon bakau besar (Rhizophora mucronata) yang memiliki indeks nilai penting sebesar $133,6 \%$.

\section{B. Saran}

1. Perlu dilakukan penelitian lanjutan untuk mengetahui nilai ekonomi total yang dimiliki hutan mangrove Desa Merak Belantung Kecamatan Kalianda Kabupaten Lampung Selatan.

2. Perlu adanya pemantauan dan peraturan yang ketat dalam pengelolaan dan pemanfaatan hutan mangrove secara lestari di hutan mangrove Desa Merak Belantung.

\section{DAFTAR PUSTAKA}

Abdul haji, R. 2001. Problem of issues affecting biodiversity in Indonesia. Situation analysis. Paper. Presented in Workshop on Tanning Net Assessment for Biodiversity Conservation in Indonesia. Bogor. Indonesia. $2-87 \mathrm{p}$.

Agustina, L., Zen, L. W., Zulfikar, A. 2014. Struktur komunitas dan valuasi ekonomi ekosistem padang lamun di perairan kawasan konservasi laut daerah Desa Berakit Bintan. Skripsi. Manajemen Sumberdaya Perairan FIKP UMRAH. Riau. p.

Alik, T. S. D., Umar, M. R., dan Priosambodo, D. 2013. Analisis vegetasi mangrove di Pesisir Pantai Mara'bombang-Kabupaten Pinrang. Jurusan Biologi Fakultas Matematika dan Ilmu Pengetahuan Alam Universitas Hasanuddin. Makasar. 1-10 p. 
Diakses pada Juli 2015. http://repository.unhas.ac.id/bitstream/handle/123456789/ 7787/ANALISIS\%20VEGETASI\%20MANGROVE\%20DI\%20PESISIR\%20PANT AI\%20MARA\%27BOMBANG\%20KABUPATEN\%20PINRANG.pdf? sequence $=3$.

Arafat, F., Wulandari C., Rommy Q. 2015. Kesediaan menerima pembayaran jasa lingkungan air sub DAS Way Betung Hulu oleh masyarahat kawasan hutan register 19 (studi kasus di desa Talang Mulya Kec. Padang Cermin Kab. Pesawaran). Jurnal Sylva Lestari. 3 (1): $1-10$ p.

Arief, A. 2003. Hutan Mangrove Fungsi dan Manfaatnya. Buku. Yogyakarta. Kanisius.

Ariftia, R. I., Qurniati, R., dan Herwanti, S. 2014. Nilai ekonomi total hutan mangrove desa Margasari kecamatan Labuhan Maringgai kabupaten Lampung Timur. Lampung. Jurnal Sylva Lestari 2 (3): 19-28 p.

Arikunto, S. 2013. Manajemen Penelitian. Buku. Rineka Cipta. Jakarta. Hal. 1-506 p.

Bengen, D. G. 1999. Pedoman teknis pengenalan dan pengelolaan ekosistem mangrove. PKSPL-IPB. Bogor. 1-13 p.

, dan I. M. Dutton. 2004. Interaction : mangrove, fisheries and forestry management in indonesia. $632-653 \mathrm{p}$.

Dinas Kehutanan Lampung Selatan. 2014. Luasan Hutan Mangrove Desa Merak Belantung. Lampung Selatan. Paper Data Dinas Kehutanan Lampung selatan. 1-2 p.

Indriyanto. 2010. Ekologi Hutan. Buku. Jakarta. Bumi Aksara. 138-172 p.

Kartawinata, K., S. Adisoemarto, S. Soemodihardjo dan I. G. M. Tantra 1979. Status pengetahuan hutan bakau di Indonesia Pros. Sem. Ekos. Hutan Mangrove: 21-39 p.

Kepel, R. Ch., L. J. L. Lumingas, dan Hendrik, B. A. Lumimbus. 2012. Komunitas Mangrove di Pesisir Namano dan Waisisil, Provinsi Maluku. Pasific Journal. 2 (7): 1350—1353 p.

Kustanti, A. 2011. Manajemen Hutan Mangrove. IPB Press. Bogor. 1-148 p.

Profil Desa Merak Belantung. 2014. Profil Desa Merak Belantung. Lampung Selatan. Desa Merak Belantung. $1-48 \mathrm{p}$.

Qodrina, L., Hamidy, R., dan Zulkarnaini. 2012. Valuasi ekonomi ekoisistem mangrove di desa Teluk Pambang kecamatan Bantan kabupaten Bengkalis provinsi Riau. Jurnal Ilmu Lingkungan. 6 (2): 93-98 p.

Saputra, S.E. 2013. Potensi wisata hutan mangrove di desa Merak Belantung kecamatan Kalianda kabupaten Lampung Selatan. Jurnal Sylva Lestari. 2 (2): 1-12 p.

Setyawan, D. A., Indowuryatno, Wiryanto, Winarno, K., dan A. Susilowati. 2005. Tumbuhan mangrove di pesisir Jawa Tengah : keanekaragaman jenis. Jurnal Biodiversitas. 6 (2): $90-94 \mathrm{p}$.

- dan Winarno, K. 2006. Permasalahan konservasi ekosistem mangrove di Pesisir kabupaten Rembang, Jawa Tengah. Biodiversitas. 7: 159-163 p. Surakarta.

Suwondo., Febrita, E., dan Sumanti, F. 2006. Struktur Komunitas Gastropoda pada Hutan Mangrove di Pulau Sipora Kabupaten Kepulauan Mentawai Sumatra Barat. Jurnal Biogenesis 2(1): 25-29 p.

Syahril, A. R. 1995. Studi Pola Sebaran Mangrove Berdasarkan Variasi Salinitas Di Pantai Malili Kabupaten Luwu. Skripsi. Jurusan Ilmu Kehutanan Unhas. Makassar. 138 p. 
Vol. 4 No. I, Januari 2016 (69-80)

Halaman ini sengaja dikosongkan 